\title{
Highly-Efficient Plasmon-Enhanced Dye-Sensitized Solar Cells Created by Means of Dry Plasma Reduction
}

\author{
Van-Duong Dao and Ho-Suk Choi * \\ Department of Chemical Engineering, Chungnam National University, 220 Gung-Dong, Yuseong-Gu, \\ Daejeon 305-764, Korea; duongdaovan@cnu.ac.kr or duongdaovan@gmail.com \\ * Correspondence: hchoi@cnu.ac.kr; Tel.: +82-42-821-5689
}

Academic Editors: Krasimir Vasilev and Melanie Ramiasa

Received: 2 February 2016; Accepted: 9 April 2016; Published: 14 April 2016

\begin{abstract}
Plasmon-assisted energy conversion is investigated in a comparative study of dye-sensitized solar cells (DSCs) equipped with photo-anodes, which are fabricated by forming gold ( $\mathrm{Au}$ ) and silver (Ag) nanoparticles (NPs) on an fluorine-doped tin oxide (FTO) glass surface by means of dry plasma reduction (DPR) and coating $\mathrm{TiO}_{2}$ paste onto the modified FTO glass through a screen printing method. As a result, the $\mathrm{FTO} / \mathrm{Ag}-\mathrm{NPs} / \mathrm{TiO}_{2}$ photo-anode showed an enhancement of its photocurrent, whereas the $\mathrm{FTO} / \mathrm{Au}-\mathrm{NPs} / \mathrm{TiO}_{2}$ photo-anode showed less photocurrent than even a standard photo-anode fabricated by simply coating $\mathrm{TiO}_{2}$ paste onto the modified FTO glass through screen printing. This result stems from the small size and high areal number density of Au-NPs on FTO glass, which prevent the incident light from reaching the $\mathrm{TiO}_{2}$ layer.
\end{abstract}

Keywords: plasmonic; dry plasma reduction; Ag nanoparticles; Au nanoparticles; dye-sensitized solar cells

\section{Introduction}

Dye-sensitized solar cells (DSCs) can achieve comparatively high conversion efficiency levels at a low fabrication cost [1]. In general, a DSC has a working electrode (WE) in the form of a nano-crystalline $\mathrm{TiO}_{2}$ electrode modified with a dye and fabricated on a transparent conducting oxide (TCO), an iodide electrolyte solution and a platinum $(\mathrm{Pt})$ counter electrode $(\mathrm{CE})$. The WE has the greatest potential to improve the efficiency of a DSC, with the efficiency defined as the light-harvesting efficiency, due to its monolayer of adsorbed dye molecules [2]. In order to improve the photocurrent, tremendous efforts have been made, including efforts to control the thickness of the $\mathrm{TiO}_{2}$ layer [3], synthesize new dyes [4] or use a scattering layer [5]. A major problem, however, is the attachment of less dye, reducing the short-circuit current density [6]. One approach to solve this problem is based on a plasmonic structure, such as silver nanoparticles (Ag-NPs) [6,7], gold nanoparticles (Au-NPs) [8] or gold nanorods [9]. Thus far, plasmonic structures have been prepared by sputtering combined with annealing [6], soaking in a colloidal silver solution for as many as 15 hours [7] or with a plasmonic paste [8,9]. These techniques, however, require toxic chemicals for the synthesis process, high temperatures for annealing, extended times for soaking or a vacuum chamber for sputtering, all indicating that developing an economic continuous process remains a challenge [10].

In order to overcome these process restrictions, we developed a new process of efficiently synthesizing supported metal-NPs by means of dry plasma reduction (DPR) [10-12]. More importantly, the developed method can operate at temperatures close to room temperature under atmospheric pressure and without using toxic chemicals. In this communication, we use the DPR method to synthesize Au-NPs and Ag-NPs on fluorine-doped tin oxide (FTO) glass substrates. The main goal of this study is to improve photocurrent generation in DSCs by studying the plasmon enhancement 
effect. This work is not only for developing a simple strategy of realizing how to improve photovoltaic properties of the DSC using NPs-coated FTO, but also for testing a potential concept of other applications, such as the optical devices, chemical catalysts and biological sensors.

\section{Results}

The overall DPR fabrication process is thoroughly described in our previous study [10]. Figure 1a,b shows the morphologies of the Ag-NPs and Au-NPs on the FTO glass substrates. As can be seen, Ag-NPs and Au-NPs with a few nanometers in size can clearly be observed to be uniformly formed on the FTO glass surfaces without any aggregation via the DPR process. This uniform and dense distribution of NPs provides high optical transmittance in the NPs on the FTO glass. As shown in Figure 1a,b, the Ag-NPs appear larger than the Au-NPs, while the areal number density of the Ag-NPs is lower than that of Au-NPs on the FTO glass. This is also supported by the Transmission Electron Microscopy (TEM) images of the Ag-NPs/Cu grid (Figure S1a, Supplementary Materials) and $\mathrm{Au}-\mathrm{NPs} / \mathrm{Cu}$ grid samples (Figure S1b, Supplementary Materials). Figure S1a shows a TEM image of Ag-NPs immobilized on a Cu grid. The average size of the Ag-NPs was measured and found to be 6-7 nm. Figure S1b presents a TEM image of Au-NPs immobilized on a $\mathrm{Cu}$ grid. The average size of the Au-NPs was in the range of 2-7 nm, typically $3 \mathrm{~nm}$ and quite small and highly mono-dispersed. Note that the particle sizes have been estimated through the ImageJ program. The average sizes of the Ag-NPs and Au-NPs on the $\mathrm{Cu}$ grid are slightly larger than that of the Pt-NPs on the $\mathrm{Cu}$ grid [10]. The size difference between the NPs corresponding to the different metal precursors on the $\mathrm{Cu}$ grids is likely due to the different electrostatic energy levels of the metal NPs. The physiochemical conversions of $\mathrm{HAuCl}_{4}$ and $\mathrm{AgNO}_{3}$ into metallic $\mathrm{Au}$ and $\mathrm{Ag}$, respectively, were further confirmed by X-ray photoelectron spectroscopy (XPS) (Supplementary Materials, Figures S2 and S3). As shown in Figure S2, the binding energy levels of the $\mathrm{Au} 4 \mathrm{f}_{7 / 2}$ and $\mathrm{Au} 4 \mathrm{f}_{5 / 2}$ electrons are 83.9 and $87.7 \mathrm{eV}$, respectively. This is consistent with Au metal, which indicates that the Au-NPs/FTO sample exists in a metallic state [13]. Additionally, after DPR, the $\mathrm{Cl}$ element composition was completely absent in the XPS spectrum (Supplementary Materials, Table S1). Hence, $\mathrm{HAuCl}_{4}$ was completely converted into metallic $\mathrm{Au}$ through the DPR process. It was also confirmed that Au-NPs were completely crystallized. The binding energy levels of the $\mathrm{Ag} 3 \mathrm{~d}_{5 / 2}$ and $\mathrm{Ag} 3 \mathrm{~d}_{3 / 2}$ electrons are 368.2 and $374.2 \mathrm{eV}$, respectively (Supplementary Materials, Figure S3), consistent with Ag metal and indicating that the Ag-NPs/FTO samples are in a metallic state [14]. Identical to the $\mathrm{Cl}$ element composition in $\mathrm{H}_{2} \mathrm{PtCl}_{6}$ [10] and $\mathrm{HAuCl}_{4}$, the $\mathrm{N}$ element composition in $\mathrm{AgNO}_{3}$ was also completely absent after DPR (Supplementary Materials, Table S2).

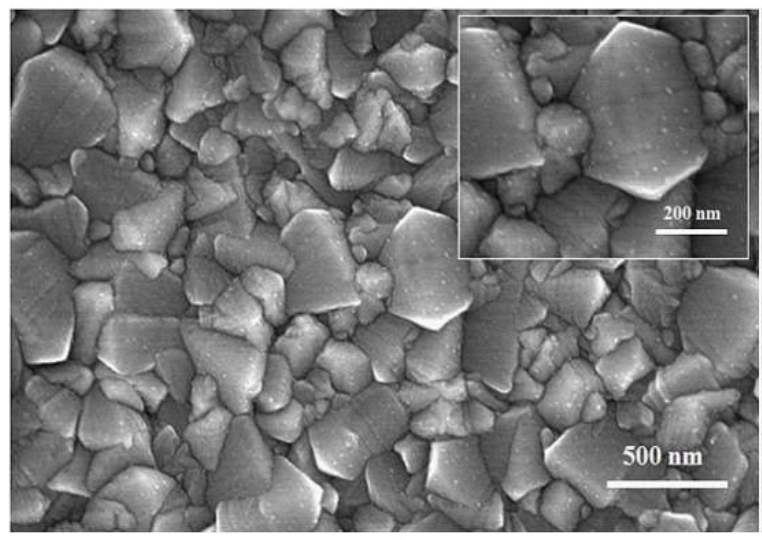

(a)

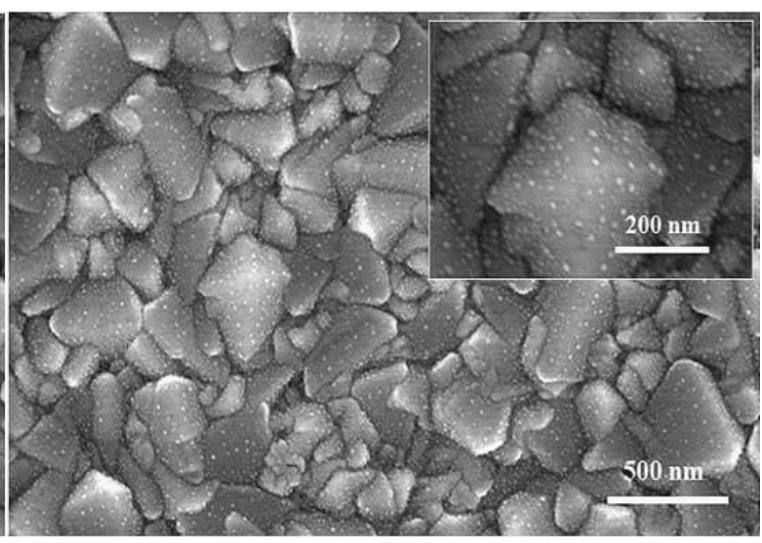

(b)

Figure 1. (a) High-Resolution Scanning Electron Microscopy (HRSEM) image of Ag-nanoparticles (NPs) on an fluorine-doped tin oxide (FTO) glass substrate; and (b) HRSEM image of Au-NPs on an FTO glass substrate. 
Figure 2 shows a comparison of the performance capabilities of the three DSCs with different working electrodes (WEs). The DSC with FTO/Ag-NPs/ $/ \mathrm{TiO}_{2}$ as the WE shows an energy conversion efficiency of $7.49( \pm 0.14) \%$, which is better than those of the DSCs with the $\mathrm{FTO} / \mathrm{TiO}_{2}$ and FTO/Ag-NPs $/ \mathrm{TiO}_{2}$ WEs, videlicet $6.54( \pm 0.15) \%$ and $6.27( \pm 0.11) \%$, respectively, as listed in Table 1. Regardless of the illumination condition, the open-circuit voltages, $V_{\mathrm{oc}}$, of the DSCs with $\mathrm{FTO} / \mathrm{Ag}-\mathrm{NPs} / \mathrm{TiO}_{2}$ and $\mathrm{FTO} / \mathrm{Au}-\mathrm{NPs} / \mathrm{TiO}_{2}$ as the WEs are slightly higher than that of the DSC with $\mathrm{FTO} / \mathrm{TiO}_{2}$ as the WE. This phenomenon is understood by considering that the Ag-NPs and Au-NPs are linked together with titania, causing a shift of the conduction band edge of titania to the negative side [15] and further increasing the gap between the Fermi level of the photoelectrode and the redox potential under illumination, which is the definition of photovoltage [16]. The short-circuit current, $J_{\mathrm{sc}}$, of the DSC with the $\mathrm{FTO} / \mathrm{Ag}-\mathrm{NPs} / \mathrm{TiO}_{2} \mathrm{WE}$, however, is slightly higher than that of the DSC with $\mathrm{FTO} / \mathrm{TiO}_{2}$ as the WE due to the low electron transfer at the $\mathrm{TiO}_{2} /$ dye/electrolyte interface [9], which was confirmed again by incident photon-to-current efficiency (IPCE) measurements and the electrochemical impedance spectroscopy (EIS) results below. In contrast, the $J_{\mathrm{sc}}$ of the DSC with $\mathrm{FTO} / \mathrm{TiO}_{2}$ as the WE is slightly higher than that of the DSC with $\mathrm{FTO} / \mathrm{Au}-\mathrm{NPs} / \mathrm{TiO}_{2}$ as the WE due to the higher Schottky barrier in the interfacial region of $\mathrm{Au}(5.1-5.5 \mathrm{eV})$ and $\mathrm{TiO}_{2}(4.0 \mathrm{eV})$, with a slight difference between the work function of $\mathrm{Ag}(4.12 \mathrm{eV})$ and the electron affinity of $\mathrm{TiO}_{2}(4.0 \mathrm{eV})$. There were some conflicts between our results and those by Lin et al. [6] for FTO/Ag-NPs $/ \mathrm{TiO}_{2}$ and by Zhang et al. [8] for FTO/Au-NPs $/ \mathrm{TiO}_{2}$. The differences in the NP size and the dense distribution were used to explain these phenomena. Indeed, the larger size and highly dense distribution of Ag-NPs mean that they could not preferentially attach to specific sites on the $\mathrm{TiO}_{2}$ surface, resulting in a decrease of the catalytic activity. In contrast, the small size and highly dense distribution of Au-NPs on FTO glass would prevent the incident light from reaching the $\mathrm{TiO}_{2}$ layer. The fill factor (FF) of the DSC with the FTO/Ag-NPs $/ \mathrm{TiO}_{2} \mathrm{WE}(67.60 \% \pm 0.68 \%)$ is higher than those of the DSCs with the $\mathrm{FTO} / \mathrm{TiO}_{2} \mathrm{WE}(61.71 \% \pm 1.16 \%)$ and the $\mathrm{FTO} / \mathrm{Au}-\mathrm{NPs} / \mathrm{TiO}_{2} \mathrm{WE}(60.60 \% \pm 1.02 \%)$ due to the low internal resistance of the cell [17]. This becomes clear when examining EIS results, as shown in Figure 3.

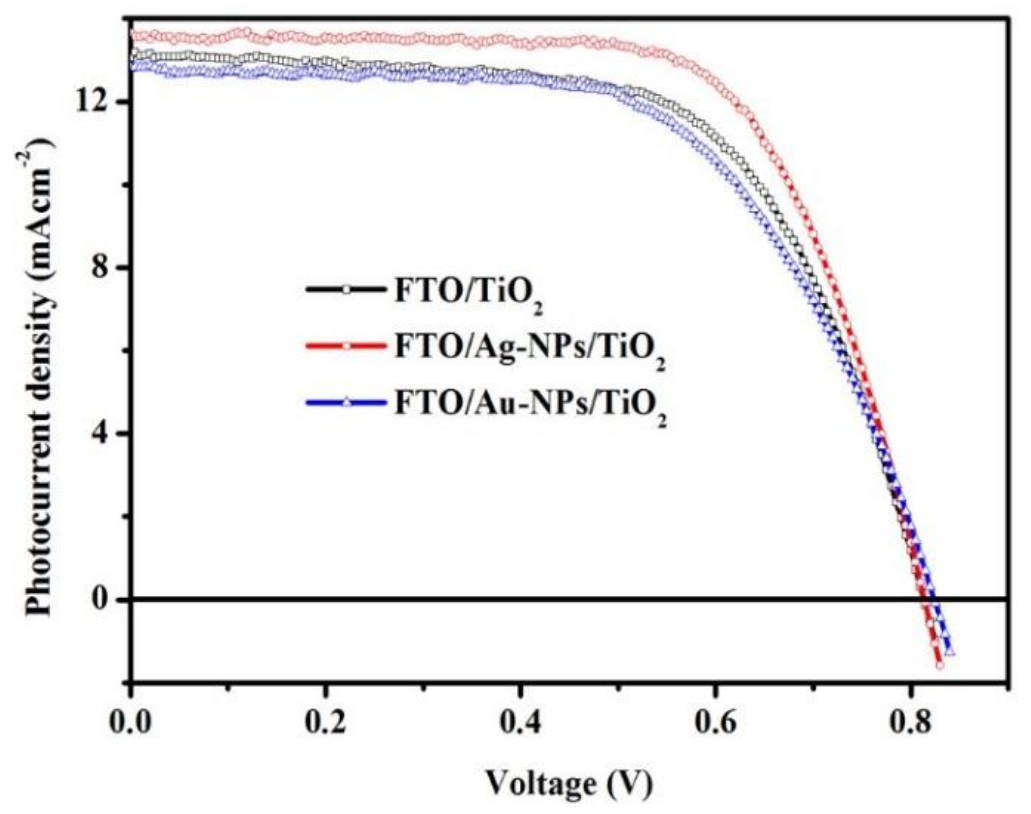

Figure 2. Current-voltage characteristics of three dye-sensitized solar cells (DSCs) equipped with different working electrodes. 
Table 1. Photoelectric performance of the three cells shown in Figure 2. $J_{\mathrm{sc}}$ : The short-circuit current; $V_{\mathrm{oc}}$ : the open-circuit voltages; FF: Fill Factor; $\eta$ : efficiency; FTO: fluorine-doped tin oxide; NPs: nanoparticles.

\begin{tabular}{ccccc}
\hline Working Electrode & $\begin{array}{c}\boldsymbol{J}_{\mathbf{s c}} \\
\left(\mathbf{m A} \cdot \mathbf{c m}^{-\mathbf{2}}\right)\end{array}$ & $\begin{array}{c}\boldsymbol{V}_{\mathbf{o c}} \\
(\mathbf{m V})\end{array}$ & $\begin{array}{c}\mathbf{F F} \\
\mathbf{( \% )}\end{array}$ & $\begin{array}{c}\eta \\
\mathbf{( \% )}\end{array}$ \\
\hline $\mathrm{FTO} / \mathrm{TiO}_{2}$ & $12.83 \pm 0.21$ & $820.00 \pm 5.00$ & $61.71 \pm 1.16$ & $6.54 \pm 0.15$ \\
$\mathrm{FTO} / \mathrm{Ag}-\mathrm{NPs} / \mathrm{TiO}_{2}$ & $13.49 \pm 0.16$ & $821.66 \pm 11.5$ & $67.60 \pm 0.68$ & $7.49 \pm 0.14$ \\
$\mathrm{FTO} / \mathrm{Au}-\mathrm{NPs} / \mathrm{TiO}_{2}$ & $12.34 \pm 0.67$ & $826.67 \pm 7.63$ & $60.60 \pm 1.02$ & $6.27 \pm 0.11$ \\
\hline
\end{tabular}

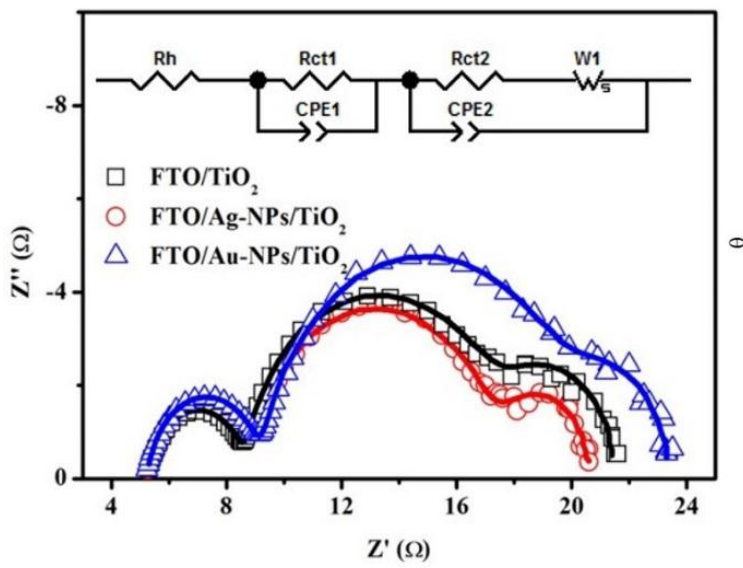

(a)

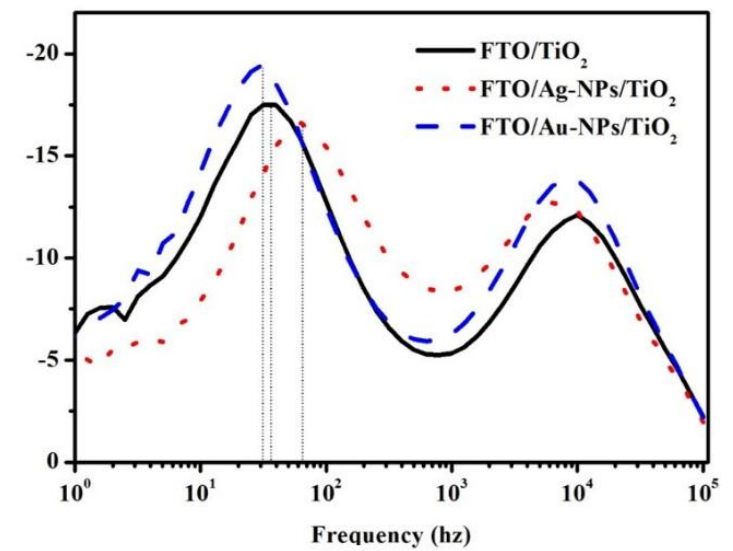

(b)

Figure 3. (a) Nyquist plots of three DSCs equipped with different working electrodes; and (b) The electrochemical impedance spectroscopy (EIS) Bode plots of three DSCs equipped with different working electrodes. Z": imaginary part of impedance; $Z^{\prime}$ : real part of impedance; CPE1: the constant phase element at counter electrode/electrolyte interface; CPE2: the constant phase element at working electrode/electrolyte interface; Rh: Ohmic internal resistance; Rct1: charge-transfer resistance at counter electrode/electrolyte interface; Rct2: charge-transfer resistance at working electrode/electrolyte interface; W1: Warburg impedance.

Figure 3a presents three Nyquist plots of DSCs with $\mathrm{FTO} / \mathrm{TiO}_{2}, \mathrm{FTO} / \mathrm{Ag}-\mathrm{NPs} / \mathrm{TiO}_{2}$ and FTO/Au-NPs $/ \mathrm{TiO}_{2}$ WEs. Table 2 shows the estimated charge transfer resistance values on both the $C E$ and WE, as well as the constant phase element (CPE) parameters for the interfaces of both the $\mathrm{CE}$ and WEs. For the purpose of comparing only the WEs, we fabricated three CEs using the same materials and method. As shown in Table 2, none of the parameters pertaining to the CE interface showed a significant difference with regard to the three DSCs. However, there was a distinct difference in Rct2 among DSCs with different WEs, as shown in Table 2. The Rct2 value of the FTO/Ag-NPs/TiO 2 sample was low, at $3.93 \Omega \cdot \mathrm{cm}^{2}$, while those of the $\mathrm{FTO} / \mathrm{TiO}_{2}$ and $\mathrm{FTO} / \mathrm{Au}-\mathrm{NPs} / \mathrm{TiO}_{2}$ samples were $4.24 \Omega \cdot \mathrm{cm}^{2}$ and $5.23 \Omega \cdot \mathrm{cm}^{2}$, respectively. For our Au-NPs immobilized on FTO, there is direct contact between the $\mathrm{Au}$ and the electrolyte, with the surface of the Au-NPs serving as a recombination site for the photogenerated electrons and triiodide ions, resulting in an increase in the charge transfer resistance in comparison to the $\mathrm{FTO} / \mathrm{TiO}_{2} \mathrm{WE}$ [8]. It is known that a lower Rct2 of a cell means faster redox kinetics of $\mathrm{I}_{3}{ }^{-} / \mathrm{I}^{-}$pairs at the photoanode/dye/electrolyte interface [18]. Hence, the electron transfer from the electrolyte to the oxidized dye became rapid, suggesting an efficient injection of electrons to $\mathrm{TiO}_{2}$ and transfer across the film to the outer circuit, reducing the rate of electron recombination [18]. This positive factor results in a high IPCE and higher power conversion efficiency. Furthermore, the reduction of the total internal resistance due to the decrease in Rct2 is the cause of the increase in the fill factor of the DSCs [17], which confirms the increase in the conversion efficiency, as previously shown. 
Table 2. Impedance parameters of three DSCs with $\mathrm{FTO} / \mathrm{TiO}_{2}, \mathrm{FTO} / \mathrm{Ag}-\mathrm{NPs} / \mathrm{TiO}_{2}$ and $\mathrm{FTO} / \mathrm{Au}-\mathrm{NPs} /$ $\mathrm{TiO}_{2}$ working electrodes (WEs), as estimated from the impedance spectra and equivalent circuit shown in Figure 3a. Rh: Ohmic internal resistance; Rct1: charge-transfer resistance at counter electrode/electrolyte interface; Rct2: charge-transfer resistance at working electrode/electrolyte interface; W1: Warburg impedance; CPE1: the constant phase element at counter electrode/electrolyte interface; $\mathrm{CPE} 2$ : the constant phase element at working electrode/electrolyte interface. Note that $\mathrm{CPE}=(\mathrm{CPE}-\mathrm{T})^{-1}(j w)^{-(\mathrm{CPE}-\mathrm{P})}$, in which $j^{2}=-1, w=$ frequency, CPE-T and CPE-P are frequencyindependent parameters of the CPE. Ws $=R \times \tanh \left([j \times T \times w]^{P}\right) /(j \times T \times w)^{P}$, where $R$ is real part of impedance; $T$ is the diffusion interpretation of Warburg element and it is given by $T=L^{2} / D$ in which $L$ is effective diffusion thickness and $D$ is diffusion coefficient of particles; $P=0.5$.

\begin{tabular}{|c|c|c|c|c|c|c|c|c|c|c|}
\hline \multirow{2}{*}{ Working Electrode } & \multirow{2}{*}{$\begin{array}{c}\mathrm{Rh} \\
\left(\Omega \cdot \mathrm{cm}^{2}\right)\end{array}$} & \multirow{2}{*}{$\begin{array}{c}\text { Rct1 } \\
\left(\Omega \cdot \mathrm{cm}^{2}\right)\end{array}$} & \multirow{2}{*}{$\begin{array}{c}\text { CPE1-T } \\
\left(\mu \mathrm{F} \cdot \mathrm{cm}^{-2}\right)\end{array}$} & \multirow{2}{*}{ CPE1-P } & \multirow{2}{*}{$\begin{array}{c}\text { Rct2 } \\
\left(\Omega \cdot \mathrm{cm}^{2}\right)\end{array}$} & \multicolumn{3}{|c|}{ Ws } & \multirow{2}{*}{$\begin{array}{c}\text { CPE2-T } \\
\left(\mu \mathrm{F} \cdot \mathrm{cm}^{-2}\right)\end{array}$} & \multirow{2}{*}{ CPE2-P } \\
\hline & & & & & & $R$ & $T$ & $P$ & & \\
\hline $\mathrm{FTO} / \mathrm{TiO}_{2}$ & 2.59 & 1.81 & 35.5 & 0.90 & 4.24 & 2.08 & 0.42 & 0.5 & 2410 & 0.90 \\
\hline $\mathrm{FTO} / \mathrm{Ag}-\mathrm{NPs} / \mathrm{TiO}_{2}$ & 2.58 & 1.85 & 36.9 & 0.89 & 3.93 & 1.73 & 0.43 & 0.5 & 2470 & 0.90 \\
\hline $\mathrm{FTO} / \mathrm{Au}-\mathrm{NPs} / \mathrm{TiO}_{2}$ & 2.56 & 1.89 & 36.1 & 0.90 & 5.23 & 1.74 & 0.40 & 0.5 & 2450 & 0.90 \\
\hline
\end{tabular}

For more information about the electron recombination lifetime of the photo-injected electrons during the photovoltaic process $\left(\tau_{\mathrm{e}}=1 / 2 \pi f_{\max } ; f_{\max }\right.$ is the maximum frequency of the peaks in the intermediate frequency region of EIS $[19,20])$, EIS Bode plots were devised. We found that the highest and lowest $f_{\text {max }}$ values were obtained with DSCs based on FTO/Ag-NPs $/ \mathrm{TiO}_{2}$ and FTO/Au-NPs $/ \mathrm{TiO} 2$ WEs, respectively. Therefore, the shortest and longest $\tau_{\mathrm{e}}$ distances were obtained for DSCs based on FTO/Ag-NPs $/ \mathrm{TiO}_{2}$ and $\mathrm{FTO} / \mathrm{Au}-\mathrm{NPs} / \mathrm{TiO}_{2} \mathrm{WEs}$, respectively. It is well known that a longer $\tau_{\mathrm{e}}$ indicates greater effective inhibition of electron recombination during the electron transfer process across WE films. Furthermore, a shorter $\tau_{\mathrm{e}}$ results in higher photoelectron collection efficiency at the FTO substrate and higher $J_{\mathrm{sc}}$ values of devices. These results are in good agreement with the current-voltage $(J-V)$ results.

Figure 4a shows the absorption spectra of only NPs layer-coated FTO glass substrate with respect to wavelength. As can be observed, the absorption spectra of AuNPs-coated FTO glass substrate becomes almost zero within the range of wavelength from 300 to $800 \mathrm{~nm}$. It was close to the absorption of FTO glass substrate. The results indicate that the plasmonic effect of AuNPs incorporated on FTO glass substrate could be neglected. However, the surface plasmonic absorption of AgNPs was clearly presented in about $400 \mathrm{~nm}$. The absorption peak of the AgNPs/FTO glass was shifted compared to the AgNPs/FTO glass in other studies [6,21] due to the broad size distribution with large AgNPs. The radiant light can be enhanced after being effectively coupled with plasmon absorption in the range of 300-600 nm due to the increase of the optical density around AgNPs [9]. According to that, there were more photons, which was usually absorbed by the dye molecules placed in the vicinity of AgNPs [21-23], resulting in the improvement of the device performance.

In order to investigate the effect of plasmonic structure on the enhancement of the photocurrent density of devices, we conducted IPCE measurements. The results are given in Figure $4 \mathrm{~b}$. As can be seen, the IPCE of the DSC fabricated with the FTO/Ag-NPs $/ \mathrm{TiO}_{2} \mathrm{WE}$ was higher than those of the DSC based on the $\mathrm{FTO} / \mathrm{TiO}_{2} \mathrm{WE}$ and the FTO/Au-NPs $/ \mathrm{TiO}_{2} \mathrm{WE}$ over the visible wavelength range. The current value calculated from the overlap integral of the IPCE spectrum agrees well with the $J_{\text {sc }}$ derived from the $J-V$ characteristics. It is well-known that the IPCE is composed of the light-harvesting and charge collection efficiencies, the efficiency of the electron injection from the excited dye into the $\mathrm{TiO}_{2}$ and the efficiency for the dye regeneration. In this study, identical compounds were used to fabricate all devices, except the WEs. Therefore, the effect of the efficiency for the dye regeneration was excluded in this work. It is reported that the plasmonic enhancement is estimated through the improvement of optical density near the metal surface. Thus, more photons could be harvested by dye located in the vicinity of the NPs, resulting in the increase of IPCE [21-23]. As we mentioned above, the plasmon effect of AuNPs/FTO glass substrate was not significant. Thus, IPCE of DSC fabricated on AuNPs/FTO was similar to that of DSC assembled on FTO glass substrate. In contrast, the IPCE 
of the device based on AgNPs/FTO glass substrate became higher than those of other two DSCs due to the transverse plasmon absorption at around $400 \mathrm{~nm}$. The result is in good accordance to Ultraviolet-visible spectroscopy (UV-Vis) data and $J-V$ results.

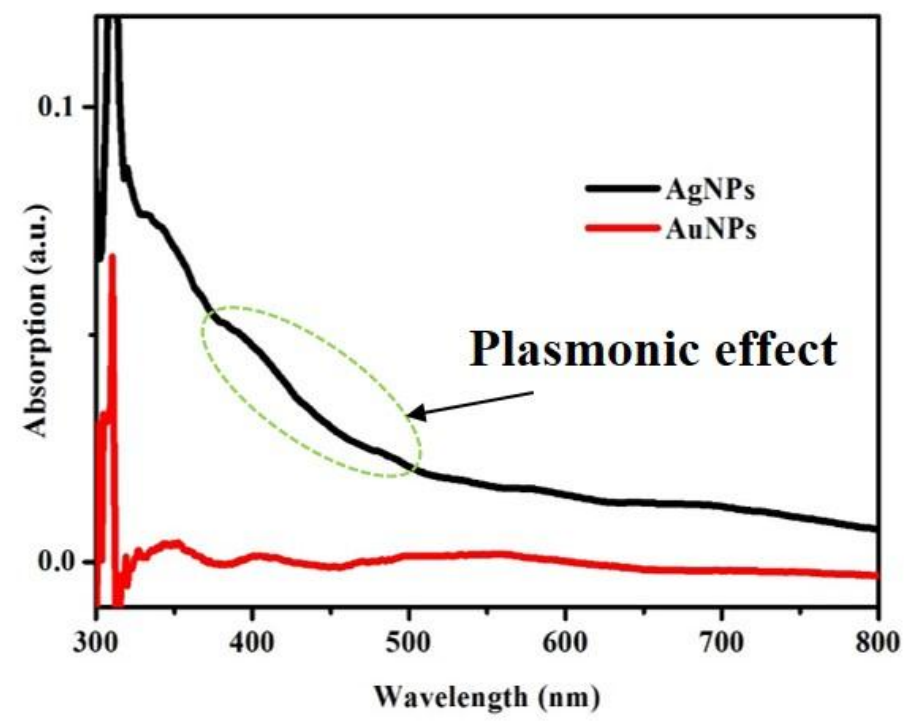

(a)

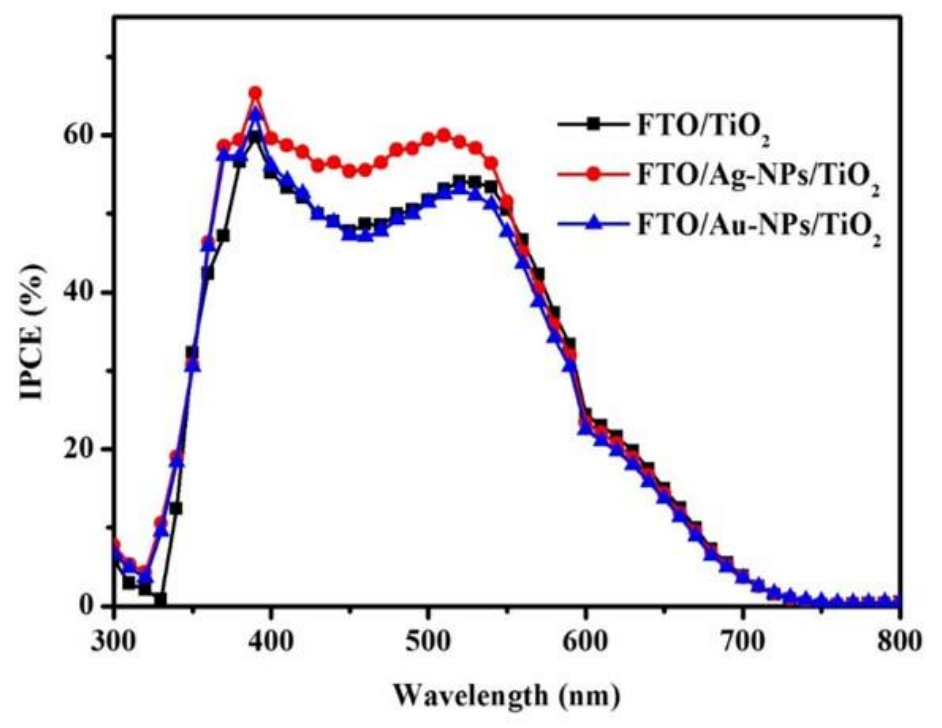

(b)

Figure 4. (a) Absorption spectra of AuNPs and AgNPs; (b) Incident photon-to-current efficiency (IPCE) spectra of DSCs based on different working electrodes. a.u.: arbitrary unit.

\section{Materials and Methods}

\subsection{Materials}

$\mathrm{H}_{2} \mathrm{PtCl}_{6} \cdot x \mathrm{H}_{2} \mathrm{O}\left(\geqslant 37.5 \%\right.$ Pt basic), $\mathrm{AgNO}_{3}(>99 \%)$ and iso-propyl alcohol (IPA) (99.5\%) were obtained from Sigma-Aldrich (St. Louis, MO, USA). $\mathrm{HAuCl}_{4} \cdot 3 \mathrm{H}_{2} \mathrm{O}$ was purchased from Aldrich. FTO glass as a conductive transparency electrode was purchased from Solaronix, Aubonne, Switzerland ( $\sim 8 \Omega$ /square). These substrates were used after cleaning them by sonication in acetone (Fluka). The nonporous $\mathrm{TiO}_{2}$ paste and ruthenium-based dye (N719) used in the study were purchased from 
Solaronix, Aubonne, Switzerland. The dye was adsorbed from a $0.3 \mathrm{mM}$ solution in a mixed solvent of acetonitrile (Sigma-Aldrich) and tert-butyl alcohol (Sigma-Aldrich) (St. Louis, MO, USA) with a volume ratio of 1:1. The electrolyte was a solution of $0.60 \mathrm{M}$ 1-methyl-3-butylimidazolium iodide (Sigma-Aldrich), $0.03 \mathrm{M} \mathrm{I}_{2}$ (Sigma-Aldrich), 0.10 M guanidinium thiocyanate (Sigma-Aldrich) and $0.50 \mathrm{M}$ 4-tert-butylpyridine (Sigma-Aldrich) in a mixed solvent of acetonitrile (Sigma-Aldrich) and valeronitrile, with a volume ratio of $85: 15$.

\subsection{Synthesis of $A u$ and Ag on FTO Glass Substrates}

Two solutions containing $10 \mathrm{mM} \mathrm{HAuCl}_{4} \cdot 3 \mathrm{H}_{2} \mathrm{O}$ in IPA and $10 \mathrm{mM} \mathrm{AgNO}$ in IPA were initially prepared. Separately, $8 \mu \mathrm{L}$ of a precursor solution were deposited onto $2 \times 2 \mathrm{~cm}^{2}$ specimens of FTO glass, and the solvent was allowed to evaporate at $70{ }^{\circ} \mathrm{C}$ for $10 \mathrm{~min}$. The specimens were then reduced using Ar plasma under atmospheric pressure at a power of $150 \mathrm{~W}$, a gas flow rate of 5 litter per minute (lpm), a treatment time of $15 \mathrm{~min}$ and a substrate moving speed of $5 \mathrm{~mm} / \mathrm{s}$ [10]. The morphologies of the Ag-NPs and Au-NPs on the FTO glass substrates were observed by high-resolution scanning electron microscopy (HRSEM). For the TEM measurements, we separately synthesized Ag-NPs and $\mathrm{Au}-\mathrm{NPs}$ on $\mathrm{Cu}$ grids under the same plasma conditions used earlier.

\subsection{Preparation of the Working Electrodes}

Three WEs were prepared on FTO, Ag-NPs/FTO and Au-NPs/FTO glass substrates. The area of $\mathrm{TiO}_{2}$ mesoporous layer and that of the TCO were $0.7 \times 0.7 \mathrm{~cm}^{2}$ and $2 \times 2 \mathrm{~cm}^{2}$, respectively. These WEs were fabricated through the following procedure. A transparent film of 20- $\mathrm{nm} \mathrm{TiO}_{2}$ particles (Solaronix, Switzerland) was coated onto the substrates by screen printing (200 T mesh), kept in a clean box for $3 \mathrm{~min}$ so that the paste could relax to reduce surface irregularities and then dried for $3 \mathrm{~min}$ at $125^{\circ} \mathrm{C}$. This screen-printing procedure (coating, storing and drying) was repeated until the thickness of the working electrode was approximately $12 \mu \mathrm{m}$. The electrodes coated with the $\mathrm{TiO}_{2}$ paste were gradually heated under an air flow at $325^{\circ} \mathrm{C}$ for $5 \mathrm{~min}$, at $375^{\circ} \mathrm{C}$ for $5 \mathrm{~min}$, at $450{ }^{\circ} \mathrm{C}$ for $15 \mathrm{~min}$ and finally at $500{ }^{\circ} \mathrm{C}$ for $15 \mathrm{~min}$ under ambient conditions [10]. After cooling to $80{ }^{\circ} \mathrm{C}$, the $\mathrm{TiO}_{2}$ electrodes were immersed in a $0.3 \mathrm{mM}$ Di-tetrabutylammonium cis-bis(isothiocyanato)bis(2,2'-bipyridyl-4,4'-dicarboxylato)ruthenium(II) (N719) dye solution in a mixture of acetonitrile (Sigma-Aldrich) and tert-butyl alcohol (Aldrich) (volume ratio of 1:1) and kept at room temperature for $24 \mathrm{~h}$ to complete the sensitizer uptake process.

\subsection{Preparation of the Counter Electrodes}

Pt CEs were also prepared through DPR, as described in our previous study [10].

\subsection{Assembly and Measurement of the DSCS}

The assembly and characterization of the DSCs were carried out as described in our previous study [10].

\section{Conclusions}

Au-NPs and Ag-NPs were successfully immobilized on FTO glass substrates by means of DPR, with the results showing homogeneous size dispersity. HRSEM and TEM images showed that the areal number density of Au-NPs/FTO was higher than that of Ag-NPs/FTO glass, while Au-NPs/FTO glass was smaller than that of Au-NPs/FTO glass. The DSC with FTO/Ag-NPs/ $\mathrm{TiO}_{2}$ as the WE demonstrated energy conversion efficiency of $7.49( \pm 0.14) \%$, which was better than those of DSCs with FTO/ $\mathrm{TiO}_{2}$ and $\mathrm{FTO} / \mathrm{Ag}-\mathrm{NPs} / \mathrm{TiO}_{2}$ WEs, viz. $6.54( \pm 0.15) \%$ and $6.27( \pm 0.11) \%$, respectively.

Supplementary Materials: The following are available online at http:/ /www.mdpi.com/2079-4991/6/4/70/s1. 
Acknowledgments: This research was supported by a National Research Foundation (NRF) grant (2014R1A2A2A 01006994), through the Korea Research Fellowship Program (2015H1D3A1061830) and by a Korea Carbon Capture and Sequestration (CCS) R\&D Center (KCRC) grant (2014M1A8A1049345). These were all funded by the Ministry of Science, ICT and Future Planning through the National Research Foundation of Korea.

Author Contributions: All authors planned the experiment and discussed the data. Van-Duong Dao prepared the manuscript, and Ho-Suk Choi reviewed it.

Conflicts of Interest: The authors declare no conflict of interest.

\section{Abbreviations}

The following abbreviations are used in this manuscript:

$\begin{array}{ll}\text { DSC } & \text { dye-sensitized solar cell } \\ \text { NPs } & \text { nanoparticles } \\ \text { FTO } & \text { fluorine-doped tin oxide } \\ \text { TCO } & \text { transparent conducting oxide } \\ \text { CE } & \text { counter electrode } \\ \text { WE } & \text { working electrode } \\ \text { DPR } & \text { dry plasma reduction } \\ \text { IPA } & \text { iso-propyl alcohol } \\ \text { EIS } & \text { electrochemical impedance spectroscopy } \\ \text { IPCE } & \text { incident photon-to-current efficiency }\end{array}$

\section{References}

1. O'Regan, B.; Gratzel, M. A Low-Cost, High-Efficiency Solar Cell Based on Dye-Sensitized Colloidal TiO 2 Films. Nature 1991, 353, 737-740. [CrossRef]

2. Gratzel, M. Conversion of Sunlight to Electric Power by Nanocrystalline Dye-Sensitized Solar Cells. J. Photochem. Photobiol. A 2004, 164, 3-14. [CrossRef]

3. Ito, S.; Zakeeruddin, S.M.; Humphry-Baker, R.; Liska, P.; Charvet, R.; Comte, P.; Nazeeruddin, M.K.; Péchy, P.; Takata, M.; Miura, H.; et al. High-Efficiency Organic-Dye-Sensitized Solar Cells Controlled by Nanocrystalline-TiO ${ }_{2}$ Electrode Thickness. Adv. Mater. 2006, 18. [CrossRef]

4. Hagfeldt, A.; Boschloo, G.; Sun, L.; Kloo, L.; Pettersson, H. Dye-Sensitized Solar Cells. Chem. Rev. $2010,110$. [CrossRef] [PubMed]

5. Ito, S.; Murakami, T.N.; Comte, P.; Liska, P.; Gratzel, C.; Nazeeruddin, M.K.; Gratzel, M. Fabrication of Thin Film Dye Sensitized Solar Cells with Solar to Electric Power Conversion Efficiency over 10\%. Thin Solid Films 2008, 516, 4613-4619. [CrossRef]

6. Lin, S.-J.; Lee, K.-C.; Wu, J.-L.; Wu, J.-Y. Plasmon-Enhanced Photocurrent in Dye-Sensitized Solar Cells. Solar Energy 2012, 86, 2600-2605. [CrossRef]

7. Standridge, S.D.; Schatz, G.C.; Hupp, J.T. Distance Dependence of Plasmon-Enhanced Photocurrent in Dye-Sensitized Solar Cells. J. Am. Chem. Soc. 2009, 131, 8407-8409. [CrossRef] [PubMed]

8. Zhang, D.; Wang, M.; Brolo, A.G.; Shen, J.; Li, X.; Huang, S. Enhanced Performance of Dye-Sensitized Solar Cells Using Gold Nanoparticles Modified Fluorine Tin Oxide Electrodes. J. Phys. D 2013, 46. [CrossRef]

9. Chang, S.; Li, Q.; Xiao, X.; Wong, K.Y.; Chen, T. Enhancement of Low Energy Sunlight Harvesting in Dye-Sensitized Solar Cells Using Plasmonic Gold Nanorods. Energy Environ. Sci. 2012, 5, 9444-9448. [CrossRef]

10. Dao, V.D.; Tran, Q.C.; Ko, S.H.; Choi, H.S. Dry Plasma Reduction to Synthesize Supported Platinum Nanoparticles for Flexible Dye-Sensitized Solar Cells. J. Mater. Chem. A 2013, 1, 4436-4443. [CrossRef]

11. Dao, V.D.; Larina, L.L.; Lee, J.K.; Jung, K.D.; Huy, B.T.; Choi, H.S. Graphene-Based $\mathrm{RuO}_{2}$ Nanohybrid as a Highly Efficient Catalyst for Triiodide Reduction in Dye-Sensitized Solar Cells. Carbon 2014, 81, 710-719. [CrossRef] 
12. Dao, V.D.; Choi, Y.; Yong, K.; Larina, L.; Shevaleevskiy, O.; Choi, H.S. A Facile Synthesis of Bimetallic AuPt Nanoparticles as a New Transparent Counter Electrode for Quantum-Dot-Sensitized Solar Cells. J. Power Sources 2015, 274, 831-838. [CrossRef]

13. Ke, X.; Zhang, X.; Zhao, J.; Sarina, S.; Barry, J.; Zhu, H. Selective Reductions Using Visible Light Photocatalysts of Supported Gold Nanoparticles. Green Chem. 2013, 15, 236-244. [CrossRef]

14. Zheng, L.; Zhang, G.; Zhang, M.; Guo, S.; Liu, Z.H. Preparation and Capacitance Performance of Ag-Graphene Based Nanocomposite. J. Power Sources 2012, 201, 376-381. [CrossRef]

15. Jakob, M.; Levanon, H.; Kamat, P.V. Charge Distribution between UV-Irradiated $\mathrm{TiO}_{2}$ and Gold Nanoparticles: Determination of Shift in the Fermi Level. Nano Lett. 2003, 3, 353-358. [CrossRef]

16. Martinson, A.B.F.; Hamann, T.W.; Pellin, M.J. New Architectures for Dye-Sensitized Solar Cells. Chemistry 2008, 14, 4458-4467. [CrossRef] [PubMed]

17. Dao, V.D.; Choi, H.S.; Jung, K.D. Effect of Ohmic Serial Resistance on the Efficiency of Dye-Sensitized Solar Cells. Mater. Lett. 2013, 92, 11-13. [CrossRef]

18. Gao, Z.; Wu, Z.; Li, X.; Chang, J.; Wu, D.; Ma, P.; Xu, F.; Gao, S.; Jiang, K. Application of Hierarchical $\mathrm{TiO}_{2}$ Spheres as Scattering Layer for Enhanced Photovoltaic Performance in Dye-Sensitized Solar Cell. CrystEngComm 2013, 5, 3351-3358. [CrossRef]

19. Kern, R.; Sastrawan, R.; Ferber, J.; Stangl, R.; Luther, J. Modeling and Interpretation of Electrical Impedance Spectra of Dye Solar Cells Operated Under Open-Circuit Conditions. Electrochim. Acta 2002, 47, 4213-4225. [CrossRef]

20. Park, J.T.; Roh, D.K.; Patel, R.; Kim, E.; Ryu, D.Y.; Kim, J.H. Preparation of $\mathrm{TiO}_{2}$ Spheres with Hierarchical Pores via Grafting Polymerization and Sol-Gel Process for Dye-Sensitized Solar Cells. J. Mater. Chem. 2010, 20, 8521-8530. [CrossRef]

21. Lin, S.J.; Lee, K.C.; Wu, J.L.; Wu, J.Y. Enhanced Performance of Dye-Sensitized Solar Cells via Plasmonic Sandwiched Structure. Appl. Phys. Lett. 2011, 99. [CrossRef]

22. Qi, J.; Dang, X.; Hammond, P.T.; belcher, A.M. Highly Efficient Plasmon-Enhanced Dye-Sensitized Solar Cells through Metal@Oxide Core-Shell Nanostructure. ACS Nano 2012, 5, 7108-7116. [CrossRef] [PubMed]

23. Ding, B.; Lee, B.J.; Yang, M.; Jung, H.S.; Lee, J.K. Surface-Plasmon Assisted Energy Conversion in Dye-Sensitized Solar Cells. Adv. Energy Mater. 2011, 1. [CrossRef]

(C) 2016 by the authors; licensee MDPI, Basel, Switzerland. This article is an open access article distributed under the terms and conditions of the Creative Commons Attribution (CC-BY) license (http://creativecommons.org/licenses/by/4.0/). 